\title{
Influence of Constructive Features of Sprayers on Fluid Flow Parameters
}

\author{
${ }^{1}$ Larisa A. Zhuravleva, ${ }^{2}$ Dmitry A. Solovyev, ${ }^{3}$ Roman N. Pavlusenko, ${ }^{4}$ Andrey N. Kuznetsov, ${ }^{5}$ Sergey V. Istomin \\ ${ }^{1-4}$ Saratov State Agrarian University named after N.I. Vavilova \\ ${ }^{5}$ Volga Inter-Regional Branch of the FSBI "VNII of Labor" of the Ministry of Labor of Russia
}

Email: rector@sgau.ru

Received: 20 ${ }^{\text {th }}$ August 2019, Accepted: $30^{\text {th }}$ September 2019, Published: $3^{\text {st }}$ October 2019

\begin{abstract}
The process of spraying a liquid has a wide range of applications in various fields of technology. The spray characteristics primarily rely on design features of the sprayers and their modes of operation. It is known that values of the flow rate and capture radius of the sprayed jets depend on the pressure, nozzle diameter, shape, size and the design features of divider. Currently, these phenomena are still insufficiently studied, however, directly or indirectly observed in practice. Consequently, a significant variety of spray gun designs has appeared. The present paper discusses the impact of the design parameters of nozzles on the flow parameters determining the characteristics of jets. Studies of the interaction of fluid flow with a divider of various shapes are also given.
\end{abstract}

Keywords

Sprayer, Radius, Flow Rate, Divider, Pressure, Speed

\section{Introduction}

The process of spraying a liquid is from the most common techniques for increasing the specific area of contact with the surface. Spraying the fluid occurs when the jet under pressure is in the gas environment. Given that the general principles of spraying fluid flow depend on the type, shape and principle of operation of the sprayer, we single out three processes of interaction (Fig. 1) [1]:

\section{Supply Pipeline}
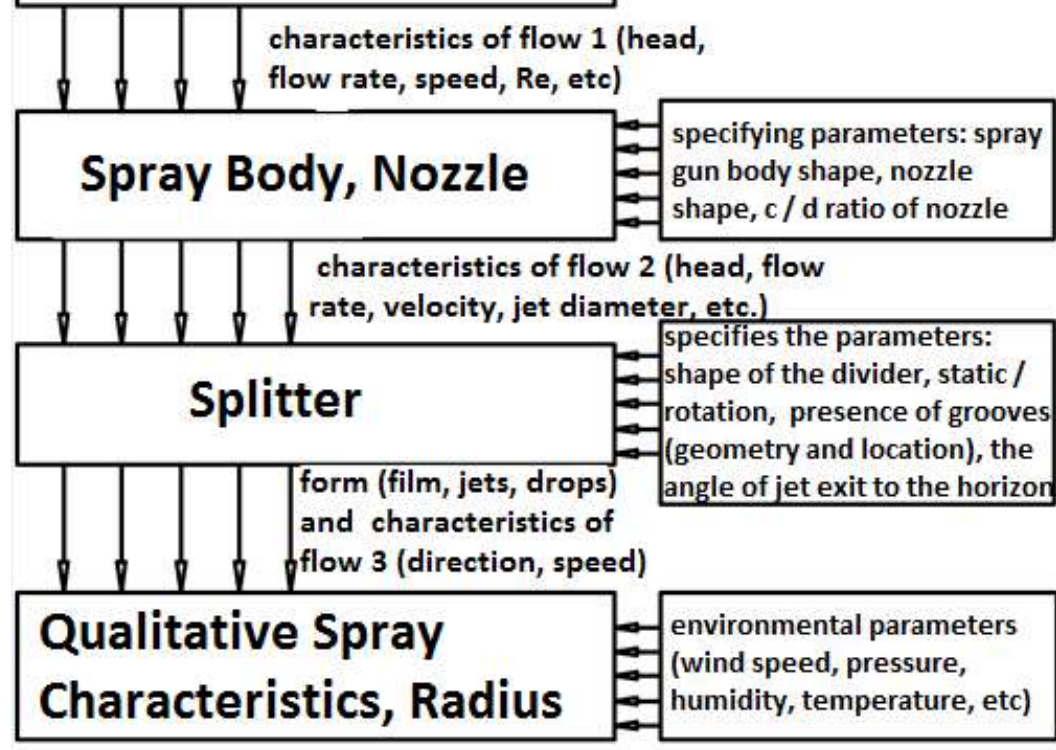

Fig. 1: Diagram of Formation of the Characteristics of Sprayed Liquid

1. Water flow through the body and the spray nozzle.

2. The interaction of water flow with the divider.

3. A descent of a film, streams or single drops of water from the divider.

The initial velocity of the jet, $\mathrm{M} / \mathrm{c}$, is determined by the following equation [2]:

$\mathrm{V}_{0}=\varphi \sqrt{\frac{2\left(\mathrm{P}_{\mathrm{d}}-\mathrm{P}_{0}\right)}{\rho_{\mathrm{B}}}} ;$

Where $\mathrm{P}_{0}$ is the atmospheric pressure, $\mathrm{MPa}$; 
$\mathrm{P}_{\mathrm{d}}$ stands for pressure at the nozzle outlet, Pascal;

$\varphi$ represents flow rate coefficient;

$\rho_{\mathrm{B}}$ is the fluid density, $\mathrm{kg} / \mathrm{M}^{3}$.

A divider is the direct working element of the dispenser. The spray characteristics (flame size, dispersion) are determined by the kinematic and geometrical parameters of the divider. The divider forms the flow regime, setting of the degree of fluid nebulization, as well as the amount of internal pulsations, which contributes to better crushing.

Rigidly fixed static smooth divider.

Nebulizer consumption, $\mathrm{M}^{3} / \mathrm{c}$, can be expressed by the flow through the hole according to the following equation [3]:

$\mathrm{Q}_{\mathrm{H}}=\mathrm{m}_{0} \omega_{0} \sqrt{2 \mathrm{gH}_{\mathrm{BX}}}$,

Where $\omega_{0}$ is the nozzle area, $\mathrm{M}^{2}$,

$\mathrm{H}_{\mathrm{BX}}$ stands for head at the sprayer inlet, $\mathrm{M}$.

The flow coefficient $\mathrm{m}_{0}$ can be expressed as [4]:

$\mathrm{m}_{0}=\left[1-(1+\zeta)\left(\frac{\omega_{0}}{\omega_{1}}\right)^{2}\right]^{-0,5}$,

$\zeta$ is the full hydraulic drag coefficient, considering the pressure loss on the surface of the divider and on the liquid-air interface.

The cross-sectional area of the flow at the exit from the divider:

$\omega_{1}=\pi \delta(2 \mathrm{r}+\delta \cos \beta)$,

Where $\delta$ is the liquid film thickness;

$2 \beta$ represents the angle at the top of the conical spreader. For flat dividers $\beta=90^{\circ}$.

The flow coefficient from the equation (2) can be expressed as follows:

$\mathrm{m}_{0}=\frac{\mathrm{Q}_{\mathrm{H}}}{\omega_{0} \sqrt{2 \mathrm{gH}_{\mathrm{BX}}}}=\frac{\mathrm{v}_{0}}{\sqrt{2 \mathrm{gH}_{\mathrm{BX}}}}=\frac{1}{\sqrt{2}} \frac{\mathrm{v}_{0}}{\sqrt{\mathrm{gH}_{\mathrm{BX}}}}=\frac{1}{\sqrt{2}} \sqrt{\frac{\mathrm{V}_{0}^{2}}{\mathrm{gH}_{\mathrm{BX}}}}=\sqrt{\frac{\mathrm{Fr}_{0}}{2}}$,

Where $\mathrm{Fr}_{0}$ is the Froude number of the incoming flow.

Cascade sprayers.

Increased productivity without changing the quality of spraying can be achieved by means of cascade multi-tiered sprayers (Fig. 2). In cascade sprays, the outer layers of the water jet are "cut off" by successively installed dividers.

We accept the flow from the nozzle of the sprayer as $\mathrm{Q}_{\mathrm{H}}, \mathrm{M}^{3} / \mathrm{c}[1]$

$\mathrm{Q}_{\mathrm{H} .}=\mathrm{m}_{0} \omega_{0} \mathrm{~V}_{0}$,

$\mathrm{V}_{0}$ is the average velocity of the fluid at the nozzle exit.

The flow rate ensuring the discharge flow of the first divider is determined by the ring area:

$\mathrm{Q}_{1 \mathrm{H} .}=\mathrm{m}_{0} \pi\left(\mathrm{r}_{0}^{2}-\mathrm{r}_{1 \mathrm{~K}^{2}}\right) \mathrm{V}_{0}$,

Where $r_{0}$ stands for the radius of the nozzle divider, $\mathrm{m}$;

$\mathrm{r}_{1 \mathrm{~K}}$ is the opening radius of the first divider, $\mathrm{M}$;

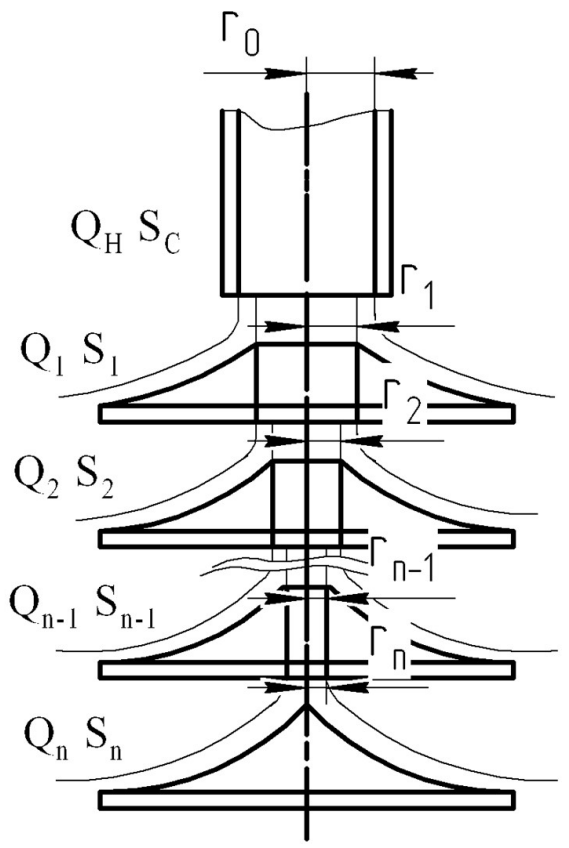

Fig. 2: Flow Distribution by Cascade Dividers Spray Bottle 
For the last splitter:

$\mathrm{Q}_{\mathrm{n} .}=\pi \mathrm{m}_{0} \mathrm{r}_{\mathrm{n}}^{2} \mathrm{~V}_{\mathrm{O}}$,

$r_{n}$ is the opening radius of the last divider.

While ensuring equal consumption from each divider:

$\mathrm{Q}_{1 \mathrm{H}}=\mathrm{Q}_{2 \mathrm{H} .}=\mathrm{Q}_{(\mathrm{n}-1) \mathrm{H}}=\mathrm{Q}_{\mathrm{nH}}=\pi \mathrm{m}_{0}\left(\mathrm{r}_{0}^{2}-\mathrm{r}_{1 \mathrm{~K}^{2}}\right) \mathrm{V}_{0}=\pi \mathrm{m}_{0}\left(\mathrm{r}_{1 \mathrm{~K}^{2}}-\mathrm{r}_{2 \mathrm{~K}^{2}}\right) \mathrm{V}_{0}=$

$=\pi m_{0}\left(r_{n-1}^{2}-r_{n}^{2}\right) V_{0}=\pi m_{0} r_{n}^{2} V_{0}$,

$\mathrm{r}_{\mathrm{n}}=0,71 \mathrm{r}_{\mathrm{n}-1}$

Therefore, given the nozzle radius of the atomizer, the parameters of the holes in the divider are selected to ensure the equal flow from all dividers. The ratio of the nozzle radius of the nozzle and the holes in the divider is 1: 0.71 .

Rotating divider.

The flow of water enters the curvilinear channels, curved in such a way that a moment of reaction force of the outgoing jet is created and the divider starts rotating around the axis, reaching a certain frequency. Subsequently, the flow enters the divider rotating at a certain frequency.

In the case when the divider is provided with grooves or grooves (Fig. 3), the equation for determining the water velocity V1 when exiting the divider will look like $[1,4]$ :

$$
\mathrm{V}_{1}=0,75 \frac{\omega^{0,8} \mathrm{D}^{0,4}}{\mathrm{~B}^{0,4}}\left(1-\frac{0,9}{\mathrm{~B}^{0,92} \dot{\omega}^{0,42} \mathrm{D}^{1,43}}\right)^{0,4},
$$

$\mathrm{B}=0,09 \mathrm{r}_{\mathrm{K}}^{0,35} v^{0,25} \mathrm{n}_{\mathrm{K}}^{0,8} \mathrm{Q}_{\mathrm{H}}^{-0,8}$ represents the parabolic grooves,

$\mathrm{r}_{\mathrm{K}}$ is the groove radius, $\mathrm{M}$;

$v$ stands for the kinematic viscosity of a fluid, $\mathrm{M}^{2} / \mathrm{c}$;

$\mathrm{n}_{\mathrm{K}}$ represents the number of grooves on the divider, units;

$\mathrm{D}^{\prime}$ is the divider diameter, $\mathrm{M}$.

An increase in the flow rate, while other things being equal, leads to an increase in the radial velocity of flow descent for all types of sprayers, and, accordingly, the radius of capture by the sprayed liquid.

The flow parameters after leaving the divider

After the jet from the divider can be divided into three areas, the plot of continuous flow is as, $1-($ about $2 \ldots 3 \mathrm{~cm})$, in some cases it may be small or absent, 2 - section of fragmented flow, 3 - sprayed area, where there is a flight of individual drops consistent with research [4-9].
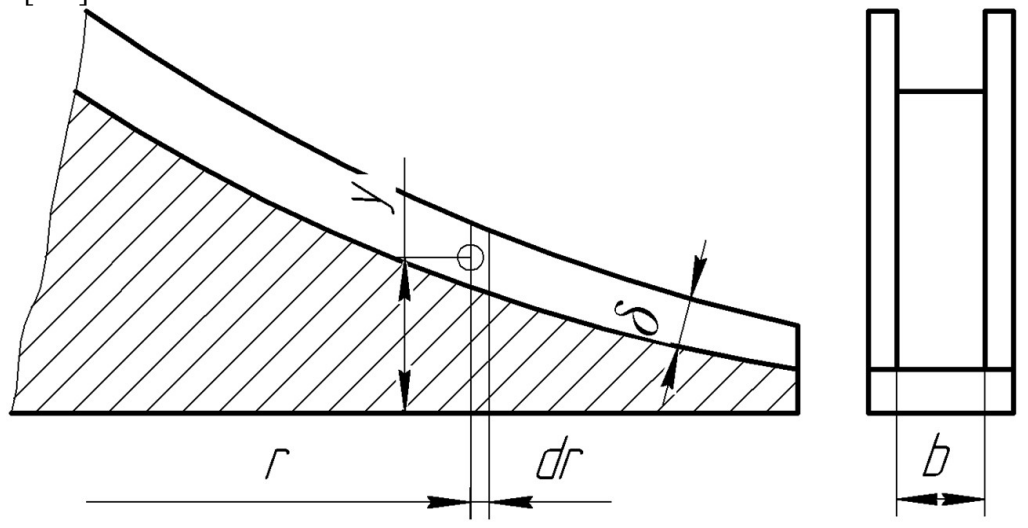

Fig. 3: Diagram of the Element of the Rotating Divider: $y$ is the Vertical Coordinate; $r$ is the Radial Coordinate; and $\delta$ represents the Thickness of the Liquid Film

The crushing mechanism of the liquid left the atomizer mainly depends on the shape of the outgoing jet and the ratio of the velocities of the jet and the surrounding gas, in turn determined by the spraying method, class and design of the atomizer. The determining factors in the length of the third section, in most cases determining the sputtering radius, is the velocity of the liquid droplets, as well as the speed and direction of the wind.

The flight distance of droplets with regard to wind can be determined by the following equation [5]:

$\mathrm{R}^{\prime}=\frac{1}{\mathrm{k}_{\mathrm{C}}}\left(\mathrm{V}_{1} \cos \alpha^{\prime}+\mathrm{V}_{\mathrm{B}}^{\prime} \cos \beta^{\prime}\right)\left(1-\mathrm{e}^{-\mathrm{tk}_{\mathrm{C}}}\right)-\left(\mathrm{V}_{\mathrm{B}}^{\prime} \cos \beta\right) \mathrm{t}$,

Where $V_{1}$ is the spray rate, $\mathrm{M} / \mathrm{c}$;

$\mathrm{V}_{\mathrm{B}}^{\prime}$ shows the wind resistance force, $\mathrm{m} / \mathrm{c}$;

$\mathrm{k}_{\mathrm{C}}$ represents the medium resistance coefficient;

$\mathrm{t}$ stands for time, c;

$\beta^{\prime}$ is the angle between the direction of the drop and the direction of the wind.

$\alpha_{0}{ }^{\prime}$ represents the angle of departure of the jet to the horizon, depending on the spray pattern.

For a range of Reynolds numbers $0<\mathrm{Re}<10^{4}$ adopted an empirical dependence of the drag coefficient $\mathrm{k}_{\mathrm{C}}$ :

$\mathrm{k}_{\mathrm{C}}=\frac{24}{\mathrm{Re}}+\frac{4,565}{\sqrt[3]{\mathrm{Re}}}-\frac{0,491}{\sqrt{\mathrm{Re}}}$

The estimated value of the Reynolds number: 


$$
\operatorname{Re}=\frac{\mathrm{v}_{1} \mathrm{~d}_{\mathrm{K}}}{\mathrm{v}_{\text {воз }}}
$$

Where $\mathrm{d}_{\mathrm{K}}$ is the droplet diameter, $\mathrm{m}$;

$v_{\mathrm{B} о 3}$ represents air kinematic viscosity, $\mathrm{m}^{2} / \mathrm{c}$.

\section{Research Methodology}

To confirm the theoretical studies, a number of nozzles with a nozzle diameter from 3 to $15 \mathrm{~mm}$ have been developed, Fig. 4.

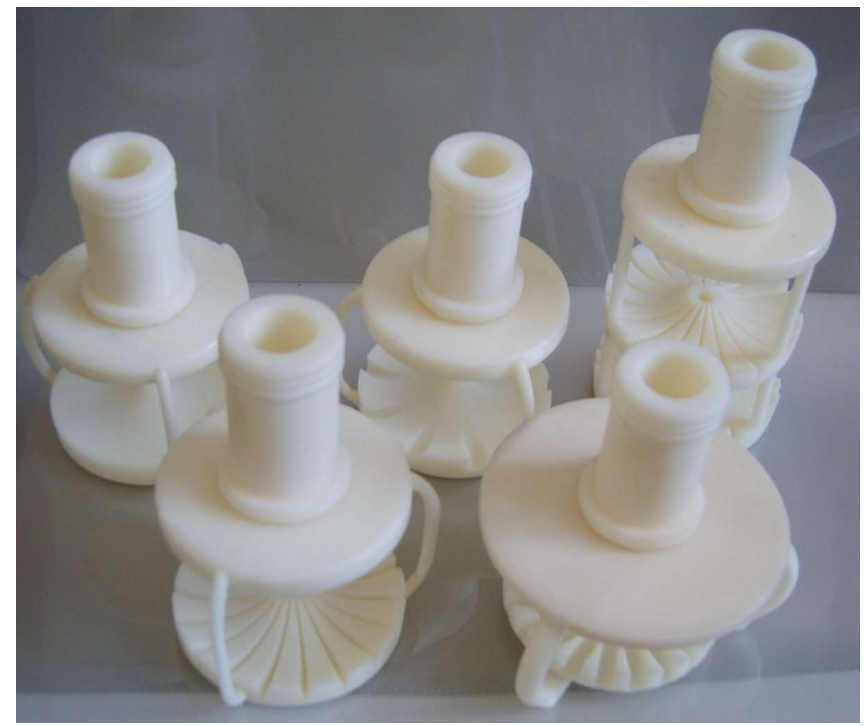

Executions sprayers made for research:

Fig.4: Polyamide Sprayers

1 - with a smooth static divider; 2 and 3 - with a static divider with grooves of triangular and semicircular shape, respectively (width from 1.5 to $5 \mathrm{~mm}$ ); 4 and 5 - with a rotating divider, triangular and semicircular grooves (the width of the grooves varied from 1.5 to $5 \mathrm{~mm}$ and their depth differed from 2 to $6 \mathrm{~mm}$ ); 6 - cascading (changing the diameters of the holes in the cones and the distance between the cones). The research fluid is water.

\section{Results of Experimental Studies}

The study has shown that with an increase in the nozzle diameter from 3 to $15 \mathrm{~mm}$ and a pressure from 0.1 to $0.35 \mathrm{MPa}$, the flow rate of the nebulizer liquid increases from 0.1 to $4.5 \mathrm{l} / \mathrm{s}$. The average value of the coefficient of fluid flow for the nebulizer is 0.80 with optimized nozzle parameters $[10,11]$.

Characteristics of the flow-pressure sprayer are shown in the graph (Fig. 5).

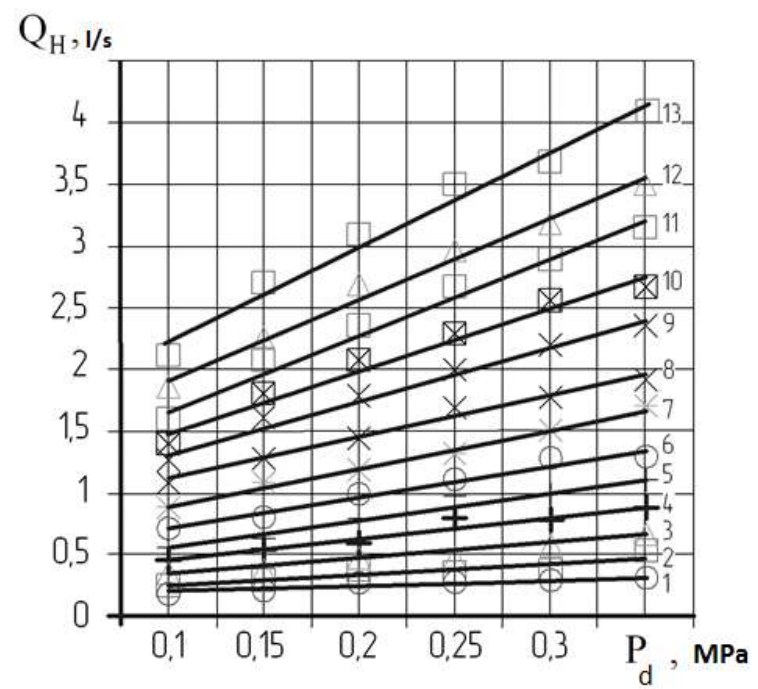

Fig. 5: Characteristics of the "Flow - Pressure" Sprayers with Different Nozzle Diameters:

$1-3 \varnothing \mathrm{mm}, \mathrm{QH}=0.485 \mathrm{Pd}+0.159, \mathrm{R} 2=0.914 ; 2-4 \varnothing \mathrm{mm}, \mathrm{QH}=0.891 \mathrm{Pd}+0.176, \mathrm{R} 2=0.911$;

$3-5 \varnothing \mathrm{mm}, \mathrm{QH}=1.24 \mathrm{Pd}+0.232, \mathrm{R} 2=0.976 ; 4-6 \varnothing \mathrm{mm}, \mathrm{QH}=1.737 \mathrm{Pd}+0.292, \mathrm{R} 2=0.957$;

$5-7 \varnothing \mathrm{mm}, \mathrm{QH}=2.217 \mathrm{Pd}+0.354, \mathrm{R} 2=0.967 ; 6-8 \varnothing \mathrm{mm}, \mathrm{QH}=2,514 \mathrm{Pd}+0.474, \mathrm{R} 2=0,973$; 
$7-9 \varnothing \mathrm{mm}, \mathrm{QH}=3.16 \mathrm{Pd}+0,57, \mathrm{R} 2=0.99 ; 8-10 \varnothing \mathrm{mm}, \mathrm{QH}=3.382 \mathrm{Pd}+0,785, \mathrm{R} 2=0,981$;

$9-11 \varnothing \mathrm{mm}, \mathrm{QH}=4.314 \mathrm{Pd}+0.904, \mathrm{R} 2=0.988 ; 10-12 \varnothing \mathrm{mm}, \mathrm{QH}=5.085 \mathrm{Pd}+0.992, \mathrm{R} 2=0,975$;

$11-13 \varnothing \mathrm{mm}, \mathrm{QH}=5.92 \mathrm{Pd}+1,134, \mathrm{R} 2=0.982 ; 12-14 \varnothing \mathrm{mm}, \mathrm{QH}=6.308 \mathrm{Pd}$

$+1.353, \mathrm{R} 2=0.984 ; 13-15 \varnothing \mathrm{mm}, \mathrm{QH}=7.6 \mathrm{Pd}+1,493, \mathrm{R} 2=0.98$.

The pressure is at the nozzle exit.

As a result of laboratory studies on the developed sprayers, it was found that the radius of the capture mainly depends on indicators such as nozzle diameter, pressure in front of the sprayer, and the height of its installation above the ground.

The maximum radius of the capture of a liquid when the diameter of the nozzle varies from 3 to $15 \mathrm{~mm}$ with a head of 0.3 $\mathrm{MPa}$ is 4.5 - $13 \mathrm{~m}$ (Figs. 6-10) [8, 10, 11].

When comparing the irrigation radius of sprinklers with a stationary divider and grooves of different size and shape, it can be concluded that the largest pickup radius is provided by type 2 and 3 sprayers with wide and deep grooves of sizes 3-5 mm, while the shape of the grooves with an equal area of transverse section and the same other parameters do not significantly affect the performance. Nevertheless, even an increase in the droplet diameter is clearly observed [10, 11].

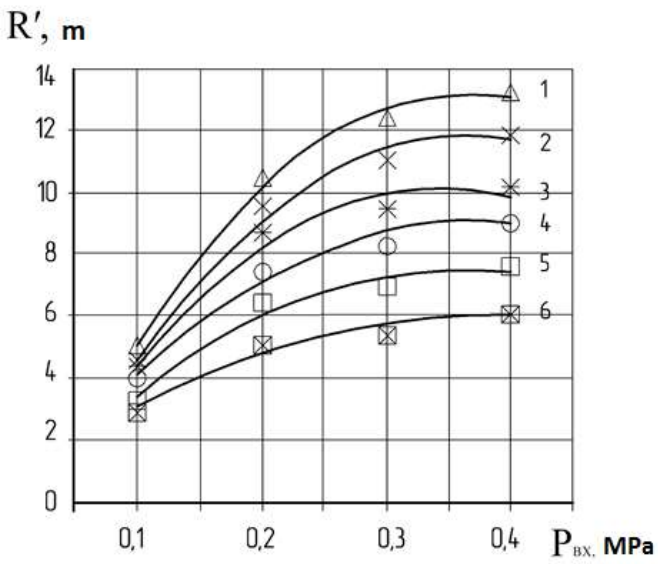

Fig. 6: Dependence of the Spray Radius on the Pressure for Nozzles for Type 1, Version 1:

$1-\varnothing 8 \mathrm{~mm}, \mathrm{R}^{\prime}=-120 \mathrm{P}_{\mathrm{BX}}{ }^{2}+86.6 \mathrm{P}_{\mathrm{BX}}-2.35, \mathrm{R}^{2}=0.994 ; 2-7 \varnothing \mathrm{mm}$,

$\mathrm{R}^{\prime}=-107 \mathrm{P}_{\mathrm{BX}}{ }^{2}+77.45 \mathrm{P}_{\mathrm{BX}}-2,125, \mathrm{R}^{2}=0,987 ; 3-6 \varnothing \mathrm{mm}$

$\mathrm{R}^{\prime}=-97.5 \mathrm{P}_{\mathrm{BX}}{ }^{2}+67.25 \mathrm{P}_{\mathrm{BX}}-1,375, \mathrm{R}^{2}=0,971 ; 4-5 \emptyset \mathrm{mm}$,

$\mathrm{R}^{\prime}=-70 \mathrm{P}_{\mathrm{BX}}{ }^{2}+51.2 \mathrm{P}_{\mathrm{BX}}-0.3, \mathrm{R}^{2}=981 ; 5-4 \varnothing \mathrm{mm}$,

$\mathrm{R}^{\prime}=-65 \mathrm{P}_{\mathrm{BX}}{ }^{2}+44.75 \mathrm{P}_{\mathrm{BX}}-0,425, \mathrm{R}^{2}=0.971 ; 6-3 \varnothing \mathrm{mm}$,

$\mathrm{R}^{\prime}=-37.5 \mathrm{P}_{\mathrm{BX}}{ }^{2}+28.45 \mathrm{P}_{\mathrm{BX}}+0,625$,

$\mathrm{R}^{2}=0.966$. Installation height $2.5 \mathrm{~m}$. Pressure before the sprayer.

Static dividers with small grooves form small dense jets, resistant to the wind, providing a greater range are shown below:

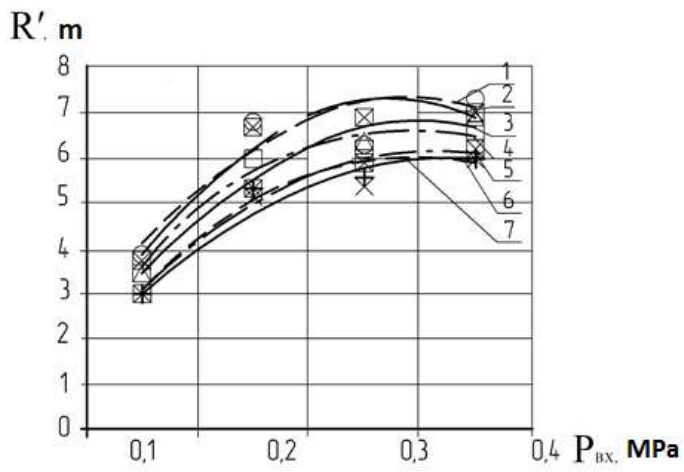

Fig. 7: Dependence of Radius on Pressure for a Sprayer with a Nozzle Diameter of 3 Ø mm and a Stationary Divider at a Height of $2,5 \mathrm{~m}$ :

$1-\mathrm{R}^{\prime}=-75.5 \mathrm{P}_{\mathrm{BX}}{ }^{2}+38.85 \mathrm{P}_{\mathrm{BX}}+0.775, \mathrm{R}^{2}=0.903$ (version 3, width $5 \mathrm{~mm}$, depth $5 \mathrm{~mm}$ );

$2-\mathrm{R}^{\prime}=-70 \mathrm{P}_{\mathrm{BX}}{ }^{2}+44,8 \mathrm{P}_{\mathrm{BX}}+0.15, \mathrm{R}^{2}=0,952$ (version 2, width $5 \mathrm{~mm}$, depth $5 \mathrm{~mm}$ );

$3-\mathrm{R}^{\prime}=-52.5 \mathrm{P}_{\mathrm{BX}}{ }^{2}+36.95 \mathrm{P}_{\mathrm{BX}}+0.375, \mathrm{R}^{2}=0.942$ (version 2, width $3 \mathrm{~mm}$, depth $3 \mathrm{~mm}$ );

$4-\mathrm{R}^{\prime}=-47.5 \mathrm{P}_{\mathrm{BX}}{ }^{2}+33.65 \mathrm{P}_{\mathrm{BX}}+0.275, \mathrm{R}^{2}=0.985$ (version 3, width $3 \mathrm{~mm}$, depth $3 \mathrm{~mm}$ );

$5-\mathrm{R}^{\prime}=-50 \mathrm{P}_{\mathrm{BX}}{ }^{2}+34.2 \mathrm{P}_{\mathrm{BX}}+0.2, \mathrm{R}^{2}=0.947$ (version 2, width $1.5 \mathrm{~mm}$, depth $1.5 \mathrm{~mm}$ );

$6-\mathrm{R}^{\prime}=-47.5 \mathrm{P}_{\mathrm{BX}}{ }^{2}+33.65 \mathrm{P}_{\mathrm{BX}}+0.275, \mathrm{R}^{2}=0.985$ (version 3, width $1.5 \mathrm{~mm}$, depth $1.5 \mathrm{~mm}$ );

$7-\mathrm{R}^{\prime}=-37.5 \mathrm{P}_{\mathrm{BX}}{ }^{2}+28.45 \mathrm{P}_{\mathrm{BX}}+0.625, \mathrm{R}^{2}=0.966$ (version 1 ). 


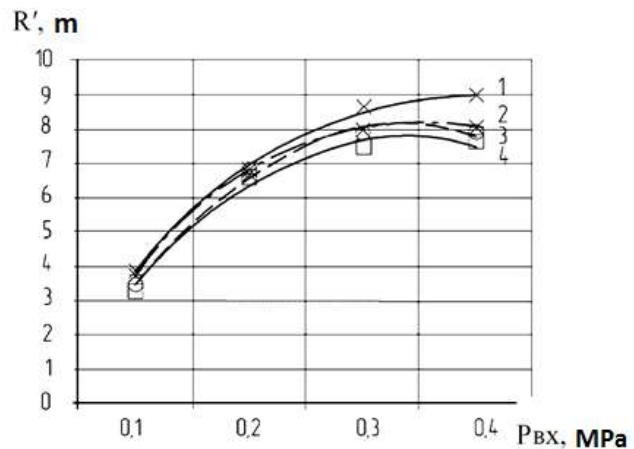

Fig. 8: The Dependence of the Capture Radius on Pressure for Nozzles with a Rotating Deflector and Nozzle Diameter of $3 \mathrm{~mm}$ :

$1-\mathrm{R}^{\prime}=-90 \mathrm{P}_{\mathrm{BX}}{ }^{2}+57 \mathrm{P}_{\mathrm{BX}}-1.35, \mathrm{R}^{2}=0.995$ (version 5, width $1.5 \mathrm{~mm}$, depth $1.5 \mathrm{~mm}$ );

$2-\mathrm{R}^{\prime}=-95 \mathrm{P}_{\mathrm{BX}}{ }^{2}+60.3 \mathrm{P}_{\mathrm{BX}}-1.55, \mathrm{R}^{2}=0.998$ (version 5, width $3 \mathrm{~mm}$, depth $3 \mathrm{~mm}$ );

$3-\mathrm{R}^{\prime}=-77.5 \mathrm{P}_{\mathrm{BX}}{ }^{2}+52.45 \mathrm{P}_{\mathrm{BX}}-0.675, \mathrm{R}^{2}=0.99$ (version 4, width $3 \mathrm{~mm}$, depth $3 \mathrm{~mm}$ );

$4-\mathrm{R}^{\prime}=-82.5 \mathrm{P}_{\mathrm{BX}}{ }^{2}+55.95 \mathrm{P}_{\mathrm{BX}}-0.925, \mathrm{R}^{2}=0.99$ (version 5, width 5mm, depth 5mm).

Installation height $2,5 \mathrm{~m}$.

By comparing the radius of the capture of sprayers with stationary dividers with a smooth surface, and sprayers with dividers with grooves and an equal diameter of the nozzle, large values of the radius of the sprayers with grooves can be observed.

From Fig. 9 it can be seen that for cascade diffusers, the irrigation radius is slightly affected by the through-hole in the divider. As for other nozzles, for cascade-type nozzles, the larger the nozzle radius is, the larger the gripping radius will be [11].

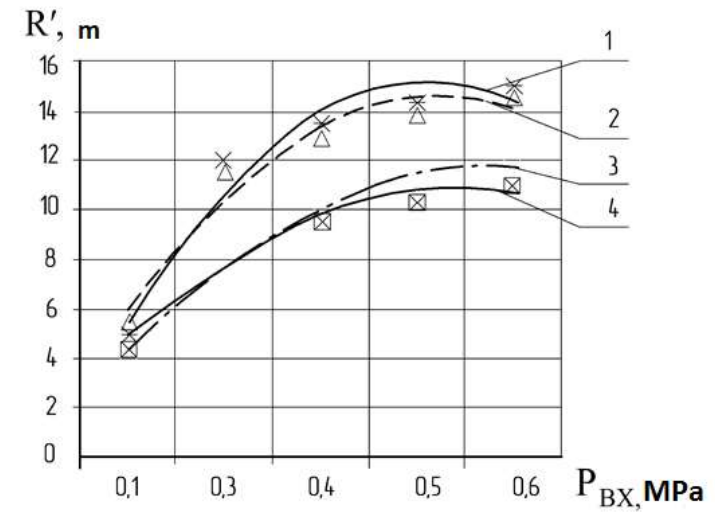

Fig. 9: Dependence of Radius on Pressure for Cascade Dispensers:

1- $\mathrm{R}^{\prime}=-131.2 \mathrm{P}_{\mathrm{BX}}{ }^{2}+94.26 \mathrm{P}_{\mathrm{BX}}-0,21, \mathrm{R}^{2}=0.971$ (nozzle diameter $15 \varnothing \mathrm{mm}$, bore diameter of the upper deflector $10 \varnothing$ $\mathrm{mm})$

2- $\mathrm{R}^{\prime}=-32.5 \mathrm{P}_{\mathrm{BX}}{ }^{2}+93.6 \mathrm{P}_{\mathrm{BX}}-0,25, \mathrm{R}^{2}=0.962$ (nozzle diameter $15 \varnothing \mathrm{mm}$, bore diameter of the upper deflector $7 \varnothing \mathrm{mm}$ ); 3- $\mathrm{R}^{\prime}=-117.5 \mathrm{P}_{\mathrm{BX}}{ }^{2}+84.25 \mathrm{P}_{\mathrm{BX}}-0.525, \quad \mathrm{R}^{2}=0.966$ (nozzle diameter $10 \varnothing \mathrm{mm}$, bore diameter of the upper deflector $7 \varnothing$ $\mathrm{mm})$

4- $\mathrm{R}^{\prime}=-142.5 \mathrm{P}_{\mathrm{BX}}{ }^{2}+97.55 \mathrm{P}_{\mathrm{BX}}-2.275, \quad \mathrm{R}^{2}=0.99$ (nozzle diameter $\varnothing 10 \mathrm{~mm}$, bore diameter of the upper deflector $5 \varnothing$ $\mathrm{mm})$.

Analysis of the experiments for all types of sprayers shows that the increased pressure contributes to the increased range of the jet. It can also be seen that when the pressure rises, the quality of sprays dramatically decreases as well as the average diameter of the droplets.

The average diameter of raindrops of sprays with a stationary smooth spreader with grooves increases with increasing the nozzle diameter and with decreasing pressure in front of the sprayer (Fig. 10). 


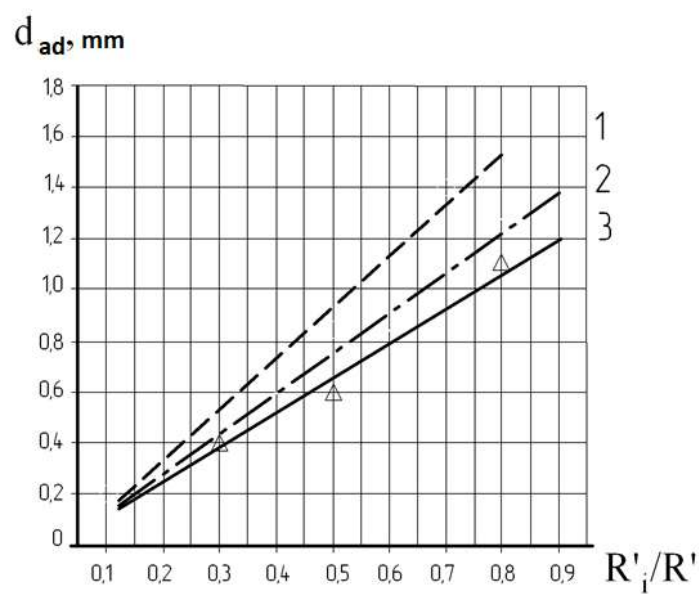

Fig. 10: Change in the Average Diameter of Droplets with an Increase in the Relative Radius of Flight of Droplets $\mathbf{R}^{\prime} \mathbf{i}$ / R' with a Nozzle Diameter of $\emptyset 6 \mathbf{~ m m}$ :

$1-\mathrm{P}_{\mathrm{BX}}=0.08 \mathrm{MPa}, \mathrm{d}_{\mathrm{CP}}=2.0 \mathrm{R}_{\mathrm{i}}^{\prime} / \mathrm{R}^{\prime}-0.06, \mathrm{R}^{2}=0,957$;

$2-\mathrm{P}_{\mathrm{BX}}=0.14 \mathrm{MPa}, \mathrm{d}_{\mathrm{CP}}=1.621 \mathrm{R}^{\prime}{ }_{\mathrm{i}} / \mathrm{R}^{\prime}-0.034, \mathrm{R}^{2}=0,969$;

$3-\mathrm{P}_{\mathrm{BX}}=0.3 \mathrm{MPa}, \mathrm{d}_{\mathrm{CP}}=1.453 \mathrm{R}_{\mathrm{i}}^{\prime} / \mathrm{R}^{\prime}-0.032, \quad \mathrm{R}^{2}=0,978$.

For nozzles with a small groove divider and a rotating divider, the droplet diameter is averagely $15-20 \%$ smaller. Considering the operation of cascade diffusers of version 6, it can be noted that they provide droplet diameters up to $1.6 \mathrm{~mm}$ at pressures higher than $0.18 \mathrm{MPa}$ and maximum nozzle diameters up to $15 \mathrm{~mm}$ [11].

With the help of dispensers with cascade dividers, it is possible to provide a sufficiently soft spraying mode at high costs.

\section{Conclusion}

Theoretical studies of the interaction between fluid flow and the structural elements of atomizer made it possible to clarify the method of calculating and selecting design parameters of the atomizers, and to design a nomenclature series for various operating conditions and operating modes.

Analysis of the collapse and flight of jets for various sprayers contributed to clarification of the dependencies determining irrigation radius and other characteristics, considering the wind speed and design of the sprayer splitter.

\section{References}

1. Ivanov I.V., Influence of Sprinkler Parameters on the Process of Water Flow Formation, Ivanov I.V.; Soloviev V.A.; Salnikov A.L.; Zhuravleva L.A., Innovations and Prospects of Modern Science, Natural Sciences, Mater conf.,Astrakhan: FGBOU VO ASTU, 2018. pp. 9-11.

2. Pagets D. G., Sprays of a Liquid; Pagez D. G.; Galustov V.S., M .: Chemistry, 1979. p. 216

3. Isaev A.P., Hydraulics and Hydromechanization of Agricultural Processes, Isaev A.P.; Sergeev B.I.; Didur V.A., M .: Agropromizdat, 1990, p.400

4. Esin A.I., Sprinkler, Esin A.I.; Boikov V.M.; Mukhin V.A.; Serebrennikov F.V.; Zhuravleva L.A., Journal of Dynamic \& Control Systems, Vol. 10, Special Issue 01, 2018, pp. 2135-2141.

5. Borodin V. A., Spraying liquids, V.A. Borodin, M.: Mashinostroenie, 1967, p. 262

6. Vukolov V.V., Development and Selection of the Working Bodies of Sprinkler Machines for Irrigation at Wind Speeds above $3 \mathrm{~m} / \mathrm{s}$ : Author, dis. Cand. Tech. Sciences, M., 1992, p. 19

7. Ryzhko N.F., Improvement of Rain-forming Devices for Multi-support Sprinkler Machines: Monograph, Ryzhko N.F., Saratov: Saratov State Agrarian University, 2009, p. 176

8. Smirnov E.V., Study of the Design and Technological Parameters of CASCADE Dockers, Smirnov E.V.; Soloviev V.A.; Salnikov A.L.; Zhuravleva L.A.,Innovative Perspectives of Modern Science, Natural Sciences, Astrakhan: FGBOU VO ASTU, 2018, pp. 16-19.

9. Chernovolov V.A., Mathematical Modeling of Liquid Distribution Processes in Agro-technologies: Monograph, Chernovolov V.A.; Kravchenko L.V., - Zernograd: Azov-Chernomorsky Engineering Institute, FSBEU VO Donskoy GAU, 2016, p. 208

10. Esin, A.I., Recommendations on the Choice of Sprinklers "CASCADE" for Sprinkling Machines, Esin A.I.; Soloviev D.A.; Zhuravleva L.A.,Melioration and Water Economy, 2018, issue 2, pp.16-22.

11. Salnikov A.L., The Results of Rxperimental Wtudies of Sprinklers "CASCADE", Salnikov A.L.; Zhuravleva L.A.; Smirnov E.V.; Solov'ev V.A., Scientific Life, 2018, issue 7, pp. 31 -37. 